\title{
Effectiveness of a Mini-Trampoline Training Program on Balance and Functional Mobility, Gait Performance, Strength, Fear of Falling and Bone Mineral Density in Older Women with Osteopenia
}

This article was published in the following Dove Press journal:

Clinical Interventions in Aging

\author{
Markus Posch' \\ Alois Schranz ${ }^{2}$ \\ Manfred Lener ${ }^{2}$ \\ Katja Tecklenburg ${ }^{2}$ \\ Martin Burtscher ${ }^{\prime}$ \\ Gerhard Ruedl' \\ Martin Niedermeier (D) \\ Werner Wlaschek ${ }^{3}$ \\ 'Department of Sport Science, University \\ of Innsbruck, Innsbruck A-6020, Austria; \\ ${ }^{2}$ Medalp Sportclinic, Imst A-6460, \\ Austria; ${ }^{3}$ Fliplab Vienna, Schwechat \\ A-2320, Austria
}

Correspondence: Markus Posch Department of Sport Science, University of Innsbruck, Fürstenweg I85, Innsbruck 6020, Austria

$\mathrm{Tel}+43512 / 507-45855$

Fax +43 512/507-45999

Email Markus.Posch@uibk.ac.at
Purpose: To evaluate the effectiveness of a combined balance-, strength-, and jumpingexercise intervention on a mini-trampoline performed by older women with osteopenia on static balance and functional mobility, gait speed, strength of the upper and lower limbs, fear of falling, as well as to investigate its influence on bone mineral density (BMD).

Patient and methods: Using a randomized controlled study design, participants (range: 56-83 years) were assigned either to the intervention group (IG; $n=20$, mean age $69.6 \pm 5.3$ years) performing a specifically tailored intervention on a mini-trampoline or to the control group (CG; $n=20,67.4 \pm 6.8$ years), that did not undertake any intervention beyond regular osteopenia treatment. The intervention was performed twice a week for 12 weeks, each session lasting 45-60 mins and consisted of balance, strength and jumping exercises. Static balance and functional mobility was measured by one-leg stance (OLS) and timed up and go test (TUG). Upper and lower limb strength was evaluated by the arm curl test (ACT) and the 30-s chair stand test (CST) whereas gait speed was measured by the $6 \mathrm{~m}$ walking test (WT). Fear of falling was measured using the Falls Efficacy Scale - International (FES-I). BMD was measured at the lumbar spine and femoral neck using Dual-energy X-ray absorptiometry (DXA).

Results: Significant interactions (group $x$ time) were found for all parameters $(p<0.001)$ except for BMD, measured at the lumbar spine $(p=0.064)$ and femoral neck $(p=0.073)$. All test parameters of balance and functional mobility tests (OLS, TUG), strength tests (ACT, CST), WT, FES-I and BMD (femoral neck) showed significant improvement in the IG $(\mathrm{p}<0.05)$.

Conclusion: The combined 12-week intervention was highly effective in improving balance and functional mobility, strength, gait performance and fear of falling in patients with osteopenia.

Keywords: osteopenia, fracture risk, risk of falling, bone mineral density, mini-trampoline, training intervention

\section{Introduction}

All people are affected by the process of aging, ${ }^{1}$ which is characterized by a loss of muscle mass, balance and impaired motor control. ${ }^{2-4}$ Related disorders negatively affect performance in static and dynamic postural control, contribute to an increased fear of falling and may therefore lead to the avoidance of daily activities with a concomitant decrease of physical function and increased risk of falling. ${ }^{5-7}$

Generally, fear of falling increases with age, which is more common among women and has been associated with an increased risk of falling ${ }^{8}$ and fall-related 
injuries. ${ }^{6}$ Approximately $28-35 \%$ of the people over 65 years fall at least once per year needing medical and hospital care following traumata. ${ }^{9}$

Especially in patients with osteoporosis and osteopenia, falls and even low-energy traumata are associated with a higher risk of fractures. ${ }^{10,11}$ Consequences of serious fall-related injuries not only reduce the quality of life but are associated with high morbidity and mortality. ${ }^{12,13}$ Generally, the hip joint and the spine are the most common sites at high risk for fracture, as the absolute number of osteoporosis-related fractures is estimated to be 700,000 vertebrae and 300,000 in hips. ${ }^{14}$

Osteoporosis and osteopenia have become a major health concern and are typically characterized by a compromised bone strength and reduced bone mineral density (BMD). ${ }^{12,15-17}$ A study by Johnell and Kanis ${ }^{18}$ reported that the average lifetime risk in a 50-year-old person to suffer from an osteoporotic fracture has been estimated at $40-50 \%$ for women and $13-22 \%$ for men.

Physical activity has been promoted as a preventive measure to improve neuromuscular and musculoskeletal functions and reduce the risk of falls in patients with reduced BMD. ${ }^{19-22}$ In order to remain independent and to be able to carry out daily activities, it is essential that older people maintain appropriate levels of strength in the lower and upper limbs as well as sufficient gait speed and good postural control. $^{23,24}$ Furthermore, based on the pathology of osteoporosis and osteopenia, it is recommended that prevention strategies should be addressed at reducing the age-related BMD loss. ${ }^{25}$ Resistance, strength exercise and generally physical activity involving impact forces improve BMD in patients, ${ }^{26}$ even if these kinds of training are not always suitable for older people who suffer from osteopenia and osteoporosis. $^{27}$

An earlier study by Kidgell et $\mathrm{al}^{28}$ presented a trampoline training program for various target groups effectively improving postural balance and exercise performance. The favorable effect of regular high-impact exercises like jumping on the skeleton originates from the physical strain that causes bone modeling, remodeling and maintaining bone mineralization. ${ }^{29,30}$ Generally, exercises on a trampoline consist of a multicomponent approach addressed at strength, postural balance training, muscle coordinative responses, joint movement amplitudes and spatial orientations. ${ }^{31}$

Although many studies investigated the importance of physical exercise in patients with lowered BMD, ${ }^{1,32-35}$ there is still no consensus on the specifications of the optimal physical intervention program to reduce risk factors for falls in patients with osteoporosis and osteopenia. $^{35,36}$ There is a large variety of combinations employed regarding the volume, intensity, type of exercise, training device and rhythm of progression of the different programs which are currently applied. ${ }^{35}$

To our knowledge, there are no studies evaluating the effects of a mini-trampoline exercise program combining exercises on balance and functional mobility, strength, gait speed, fear of falling and BMD in females with osteopenia, as although fear of falling and prevalence of lowered BMD is more common among females.

Therefore, the aim of this study was to evaluate the effectiveness of a combined balance-, strength-, and jumping-exercise intervention on a mini-trampoline performed by older women with osteopenia on static balance and functional mobility, gait speed, strength of the upper and lower limbs, fear of falling, as well as to investigate its influence on the metabolism of BMD.

\section{Methods}

\section{Study Design}

This project was carried out in cooperation with the Fliplab Vienna (Austria), where the exercise intervention program took place between September and November 2018. Potential study participants were recruited in January 2018 by creating adverts in the local newspapers, television and with the help of personal connections. Each of the participants $(n=54)$ contacting the research group via phone obtained information about characteristics and conditions of the whole study project. After considering all inclusion and exclusion criteria, potential participants visited the Fliplab to agree to participate in the study, the final sample consisted of 43 females.

Using a randomized controlled study design (see supplementary CONSORT checklist for details), participants were randomly assigned (using a numbered series of prefilled envelopes specifying the group) either to the intervention group (IG) or to the control group (CG). A flowchart used for the acquisition of participants is presented in Figure 1.

Informed written consent was obtained from all participants. This study was conducted in conformity with the ethical standards of the 2008 Declaration of Helsinki. Furthermore, the study was approved $(02 / 2018)$ by the Institutional Review Board (IRB) of the Department of Sport Science as well as the Board for Ethical Issues (BfEI) of the University of Innsbruck. 


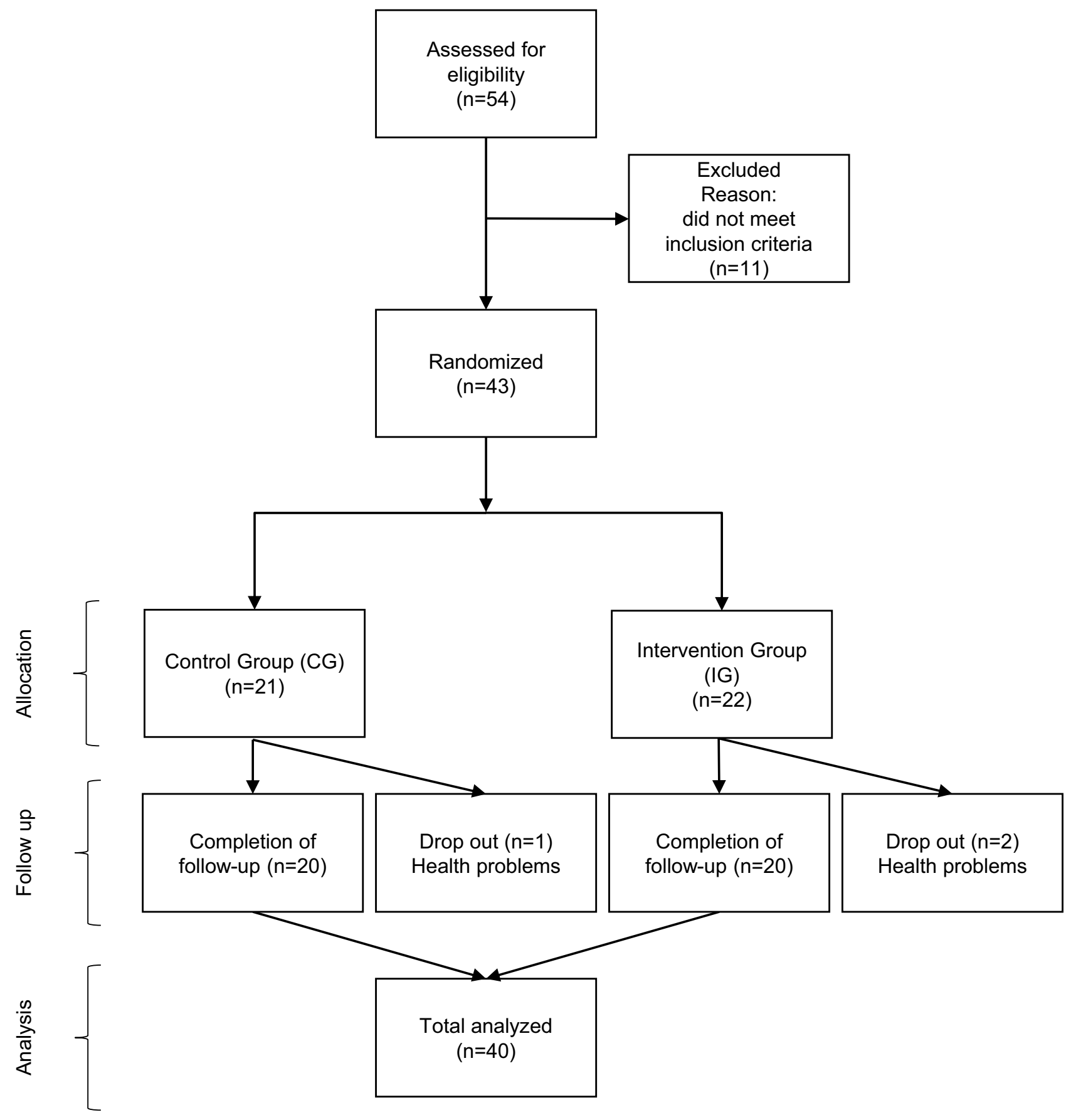

Figure I Flowchart presenting the acquisition of participants.

\section{Participants}

A total of 40 adults with a mean age of $68.5 \pm 6.1$ years (range: 56-83 years) agreed to volunteer for this study. Of the initial 43 participants, two adults in the IG and one adult in the CG dropped out of the study during the intervention period due to health problems not related to the exercise program.

Inclusion criteria were female sex, a clinically diagnosed osteopenia (i.e. T-score $\leq-1.0$ standard deviation at the femoral neck and lumbar spine) determined by Dual- energy X-ray absorptiometry (DXA) at maximum 12 months prior to enrolment and age of $>55$ years.

Prior to the beginning of the project, study participants were asked to visit their general practitioner and get a verbal approval for study participation after screening for medical contraindications.

Exclusion criteria included any medical contraindications (visual deficiency, severe auditive or vestibular deficiency, advanced locomotor diseases, neurological and 
cardiovascular diseases, severe orthopedic conditions and incapacity to perform the exercise intervention) or planned absence of more than 3 weeks during the study period. Furthermore, participants with values for the Barthel Index ${ }^{37}$ lower than 85 were excluded.

Eligible participants were randomized into two groups (IG and CG) by a researcher (AS) unaware of the intervention procedures.

The IG ( $\mathrm{n}=20$, mean age $69.6 \pm 5.3$ years) followed a combined 12-week exercise intervention program on a minitrampoline, while participants of the CG $(n=20,67.4 \pm$ 6.8 years) continued with the usual osteopenia therapy. Participants were asked not to change their daily habits during the study period. According to Otero et al, ${ }^{35}$ all CG participants were phoned three times to remind them no to modify their daily habits until they had completed the post intervention tests. IG and CG participants were informed that they have to carry out several tests twice, pre and post intervention, within a time interval of 12 weeks between the tests. At the end of the project, CG participants were informed about the results of the study and received information about an exercise intervention program most suitable for them. Furthermore, the same exercise training intervention program was offered to all members of the CG. All CG participants ( $\mathrm{n}=20$ ) took the opportunity of performing the exercise program after study completion.

\section{Exercise Program}

The intervention was designed by an interdisciplinary team of exercise scientists, physiotherapists and physicians based on the latest findings of clinical interventions in aging. ${ }^{38-40}$ Fliplab instructors were trained and instructed prior to the study by MP to become familiar with the training intervention program.

According to a study by Lesinski et al, ${ }^{40}$ which evaluated the dose-response relationships of balance training modalities, that could maximize improvements in balance performance in older adults, the training intervention program was performed twice a week for 12 weeks, each session lasting 45-60 mins.

All training sessions were led by experienced instructors. The whole training on the mini-trampoline (Trimilin Austria, diameter $1.02 \mathrm{~m}$ ) was performed in small groups of five to eight participants to enable a favorable supervisory relationship. Supporting bars were mounted on the mini-trampoline to protect the participants from falling (Figure 2). In addition to the mini-trampoline, tennis balls, thera bands and balloons were used as further training tools to increase exercise difficulty.

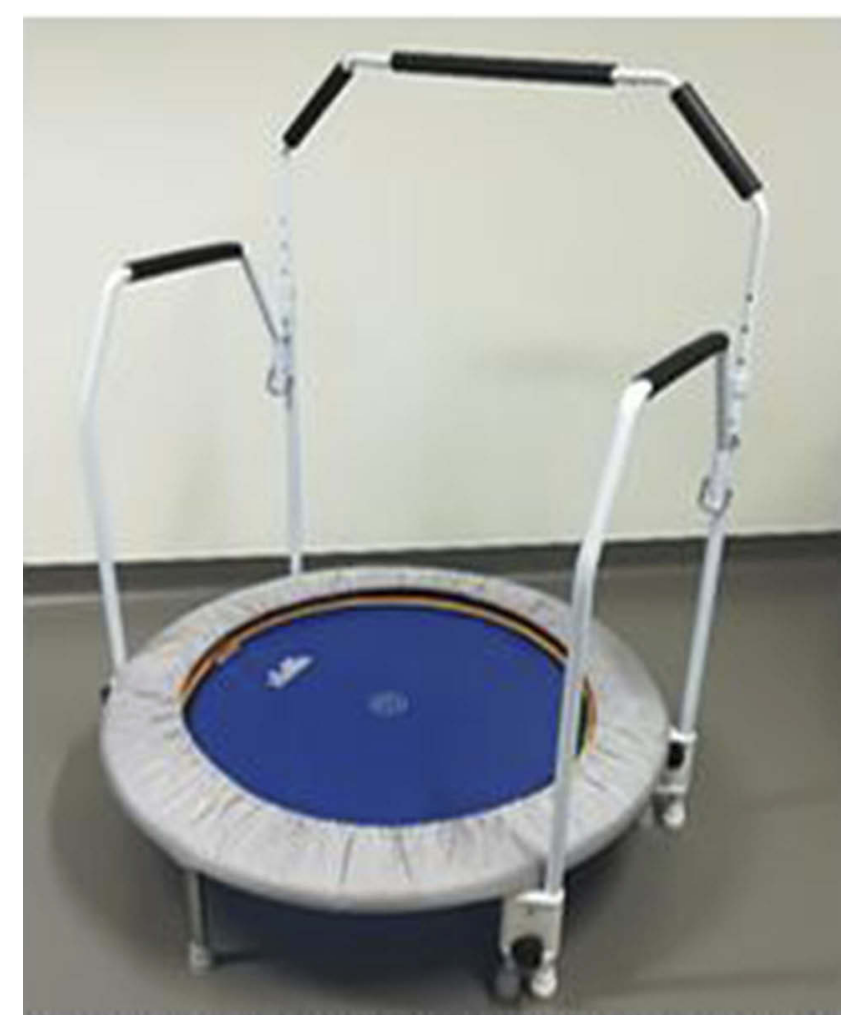

Figure 2 The used mini-trampoline in the training intervention program.

Balance exercises consisted of walking in place and static exercises like, two-legged stance, shifting weight while standing, semi-tandem stance, lunge, tandem stance, heel or toe stances and one-leg stance. All balance tasks could be done with eyes open or closed, or alternately with the left or right leg in front to increase task difficulty. Moreover, IG participants were given balance exercises under single- (only balance tasks) and dual-task conditions (additional motor tasks). Motor tasks included moving arms, balancing a balloon with the index finger, throwing and catching balls. Generally, balance exercises were designed to progressively reduce the base of support, to disturb the center of gravity, to stress postural muscle groups and to diminish sensory input as recommended by the American College of Sports Medicine. ${ }^{41}$

Strength exercises aimed at improving muscular strength and strength endurance from the lower and upper limbs and trunk. All exercises to enhance muscle strength were performed on the mini-trampoline and consisted of squats, abduction and adduction of the legs, flexion and extension of the elbow joint, abduction and adduction of the arms, anteversion and retroversion of the shoulder joint.

Jumping exercises were performed on the minitrampoline to reduce the possibility of jump-related 
injuries and consisted of bouncing in place, bouncing with feet in a semi-tandem and tandem stance, jumping with feet together or with scissor steps (to the front, back, right or left), jumping combined with rotations around the longitudinal axis and jumping on one leg.

An experienced instructor was present at each training session to ensure the participants' safety and to make a progression of the training exercises possible. According to Ramalho et $\mathrm{al}^{42}$ the training intervention program was divided in three different phases. In Phase 1 (4 weeks), focus was on adaption and learning of the execution technique of all the exercises used in the intervention. Phase 2 (4 weeks) aimed at improving muscular strength and balance whereas Phase 3 (4 weeks) dealt with maintaining improvements.

Participants were ordered to achieve a high training adherence. By offering extra dates, each participant attended 24 of $24(100 \%)$ possible training sessions. According to Otero et al, ${ }^{35}$ a series of strategies (giving plenty of positive feedback; conversations with all participants in each of the sessions; sharing the importance of feeling secure) were carried out to achieve a pleasant atmosphere while training.

\section{Outcome Measures}

Measurements were performed one day before the start (pretest) and one day after the completion (post-test) of the specific training intervention program. The tests were conducted by the principal investigator (MP) and took place in a separated room at the same center where the intervention program was carried out (Fliplab Vienna, Austria). The principal investigator was not involved in the intervention training program and was blinded to group allocation. Participants were instructed to use the same clothing and to perform both, pre- and posttests barefoot. At the beginning of the testings, questionnaires were filled out. After a standardized warming-up, participants had to perform the physical tests. Baseline testing included a learning session where the participants performed all physical outcome measures once.

\section{Personal and Demographic Data Questionnaire}

A questionnaire was used to assess demographic data and study participants were further asked on/about age, weight, height.

\section{Static Balance}

For measuring the static balance, the one-leg stance (OLS) was used. ${ }^{43}$ Study participants were told to stay alternately on the right and left leg for as long as possible (maximum
$30 \mathrm{~s}$ ), with their hip and knee slightly flexed, arms hanging down and eyes opened. ${ }^{44-46}$ The evaluated means of measured time regarding all three measurements on each leg were considered for the statistical analysis. The OLS is a valid test and described as a method of quantifying static balance ability in older adults. ${ }^{47,48}$

\section{Functional Mobility}

Functional mobility was measured using the timed up and go test (TUG) that is commonly used in frail and older people. $^{49}$ Participants were given verbal instructions to rise from a chair, walk $3 \mathrm{~m}$ to a line on the floor, turn around, walk back and sit down again. ${ }^{50}$ Moreover, participants were allowed to make use of one practice trial to become familiar with the procedure. The required time to complete the task was recorded. According to ShumwayCook et al, ${ }^{50}$ the TUG is a sensitive and specific measure of probability for falls among older adults.

\section{Upper Limb Muscle Strength}

The arm curl test (ACT) was used to measure upper limb muscle strength. The tests determine the maximum number of times a dumbbell (2.3 kg for females) can be curled through a full range of motion in $30 \mathrm{~s}$ while being seated on a chair. ${ }^{51}$ The ACT is a good indicator of overall upper body strength and has a good criterion validity $(\mathrm{r}=0.81){ }^{51}$

\section{Lower Limb Muscle Strength}

Reflecting lower body strength, the 30-s chair stand test (CST) was used in this study. The task for all participants was to rise to a full stand from a seated position on a chair by not pushing off with the arms, maintaining their arms crossed at the level of the chest. ${ }^{35,51}$ Total number of stand-ups was recorded. The high correlation $(r=0.77)$ supports the criterion validity of the CST as this test is also capable of detecting the effects of physical training in older adults. ${ }^{52}$

\section{Gait Speed}

As gait speed is a strong independent predictor of selfreported perceived function ${ }^{53}$ as well as a good indicator of functional balance, physical performance and falls in older adults, ${ }^{54-56}$ the $6 \mathrm{~m}$ walking test (WT) was conducted in this study. In accordance with Konak et al, ${ }^{33}$ the task was to walk $10 \mathrm{~m}$ at a comfortable and secure pace and the time to reach a predefined distance of $6 \mathrm{~m}$ was measured with a stopwatch. Participants were allowed to conduct one practice trial prior to the two evaluation trials. The mean of the two trials was 
considered for statistical analysis among the WT, which is a reliable measure $(\mathrm{r}=0.97)$ in COPD patients as well. ${ }^{57}$

\section{Falls Efficacy}

The Falls Efficacy Scale - International (FES-I) was developed to document fall-related self-efficacy in older people and represents a modification of the original falls efficacy scale. ${ }^{58,59}$ Furthermore, the FES-I is a measure of fear of falling representing a valid and reliable instrument and consists of 16 items on complex functional performances and social aspects of falls. ${ }^{59,60}$ A study by Dias et $\mathrm{al}^{59}$ proved that the FES-I shows high internal reliability (Cronbach's $\mathrm{a}=0.96$ ) as well as high test-retest reliability $(\mathrm{r}=0.96)$.

\section{Bone Mineral Density}

BMD measurements, carried out by one radiology department, were made at the proximal femur (at the neck, Ward's triangle, trochanter) and lumbar spine (at L1-L4) using DXA (Hologic Discovery $\mathrm{Ci}$, Hologic Inc.) pre and post intervention. The measurements were made without knowledge of the group to which the participants belonged, and analysis was carried out in accordance with the manufacturer's recommendations. For BMD values to be clinically useful, they have to be compared to established normative ranges. ${ }^{61,62}$ Values were therefore expressed as absolute values $\left(\mathrm{g} / \mathrm{cm}^{2}\right)$ and T-Scores. The T-score expresses the number of standard deviations that the measured BMD differs from the sex-matched young normal (age 25-30 years) value. ${ }^{61,63}$ The primary outcomes for this study were absolute changes in BMD and its standard deviation at the femoral neck and lumbar spine (L1-L4), as assessed by DXA.

\section{Statistics}

Data of study participants are presented as means and standard deviations as well as absolute frequencies. Pursuant to tests of normal distribution (Kolmogorov Smirnov), differences at pre-test in OLS, TUG, ACT, CST, WT, FES-I and BMD between IG and CG were evaluated either by independent t-tests or Mann-
Whitney- $U$ tests. The primary analysis consisted of a series of mixed analysis (group $\mathrm{x}$ time) of variances to evaluate the interaction of the within-subjects factor (time: pre- vs post-tests) and between-subjects factor (group: IG vs CG) and thus to explore the effectiveness of the intervention program. Furthermore, intragroup comparisons were conducted using dependent t-tests or Wilcoxon tests. To evaluate the measured changes (pre and post), the percentage of all changes $(\Delta \%)$ was calculated. SPSS 23.0 (IBM Corporation, Armonk, NY, USA) was used for statistical analysis. All p-values were two-tailed and values of $p<0.05$ were considered to indicate statistical significance.

\section{Results}

\section{Preliminary Analysis}

Mean age, height, body mass and body mass index of study participants at baseline are listed in Table 1. No significant differences were found within demographic data like age, height, body mass and body mass index between IG and CG participants ( $p>0.05)$ pre intervention. Furthermore, no significant differences were detected among OLS, TUG, ACT, CST, WT, FES-I and BMD between the two groups at baseline $(p>0.05)$. No exercise-related injuries or medical incidences occurred while either performing the training intervention program nor completing the whole test battery.

\section{Primary Analysis}

The test parameters of static balance and functional mobility tests (OLS, TUG), strength tests (ACT, CST), WT and FES-I showed significant group by time interactions indicating different changes in the parameters between IG and CG (Table 2). BMD did not show a significant group by time interaction. There was a tendency with a medium effect size for significant interaction (group $\mathrm{x}$ time) regarding BMD measured at the lumbar spine $\left(\eta^{2}=0.087\right)$ and the femoral neck $\left(\eta^{2}=0.082\right)$. Intragroup comparisons including percentage of changes are specified for each test parameter separately.

Table I Baseline Characteristics of Study Participants

\begin{tabular}{|l|l|l|l|l|}
\hline & Total Group $(\mathbf{n}=\mathbf{4 0})$ & Intervention Group $(\mathbf{n}=\mathbf{2 0})$ & Control Group $(\mathbf{n}=20)$ & $\mathbf{p}$-value \\
\hline Age [years] & $68.5 \pm 6.1$ & $69.6 \pm 5.3$ & $67.4 \pm 6.8$ & 0.296 \\
Height [cm] & $160.8 \pm 5.2$ & $160.0 \pm 5.0$ & $161.6 \pm 5.4$ & 0.594 \\
Body mass [kg] & $64.0 \pm 9.2$ & $64.2 \pm 8.1$ & $63.8 \pm 10.5$ & 0.893 \\
Body mass index [kg/m $\left.{ }^{2}\right]$ & $24.8 \pm 3.4$ & $25.1 \pm 3.2$ & $24.4 \pm 3.7$ & 0.530 \\
\hline
\end{tabular}

Note: Data are presented as mean values \pm standard deviations. 
Table 2 Comparison of Pre- and Post-Test Results Between IG and CG

\begin{tabular}{|c|c|c|c|c|c|c|c|c|}
\hline & \multicolumn{3}{|c|}{ Intervention Group ( $\mathrm{N}=\mathbf{2 0})$} & \multicolumn{3}{|c|}{ Control Group ( $\mathrm{N}=20)$} & \multirow{2}{*}{$\begin{array}{l}\text { p-value (Group } \\
\times \text { Time } \\
\text { Interaction) }\end{array}$} & \multirow[t]{2}{*}{ Effect Size } \\
\hline & Pre & Post & $\Delta \%$ & Pre & Post & $\Delta \%$ & & \\
\hline OLS left [s] & $17.99 \pm 7.57$ & $23.91 \pm 7.04^{\mathrm{a}, \mathrm{b}}$ & 32.97 & $21.76 \pm 6.77$ & $19.92 \pm 9.57$ & -8.46 & $<0.001$ & $\eta^{2}=0.354$ \\
\hline OLS right $[\mathrm{s}]$ & $17.80 \pm 7.35$ & $23.58 \pm 7.17^{\mathrm{a}, \mathrm{b}}$ & 32.51 & $21.77 \pm 8.10$ & $18.79 \pm 8.98$ & -13.70 & $<0.001$ & $\eta^{2}=0.306$ \\
\hline TUG $[s]$ & $5.83 \pm 0.95$ & $4.72 \pm 0.83^{\mathrm{a}, \mathrm{b}}$ & -19.09 & $5.45 \pm 1.02$ & $5.89 \pm 0.96^{\mathrm{a}}$ & 8.23 & $<0.001$ & $\eta^{2}=0.611$ \\
\hline $\mathrm{ACT}[\mathrm{n}]$ & $15.95 \pm 2.93$ & $21.50 \pm 3.62^{\mathrm{a}, \mathrm{b}}$ & 34.80 & $16.80 \pm 3.35$ & $17.40 \pm 3.35$ & 3.57 & $<0.001$ & $\eta^{2}=0.580$ \\
\hline CST [n] & $15.55 \pm 3.40$ & $21.20 \pm 3.04^{\mathrm{a}, \mathrm{b}}$ & 36.33 & $16.30 \pm 3.01$ & $16.65 \pm 3.54$ & 2.15 & $<0.001$ & $\eta^{2}=0.576$ \\
\hline $\mathrm{WT}[\mathrm{m} / \mathrm{s}]$ & $1.46 \pm 0.33$ & $1.82 \pm 0.30^{\mathrm{a}, \mathrm{b}}$ & 24.52 & $1.60 \pm 0.47$ & $1.50 \pm 0.42$ & -6.19 & $<0.001$ & $\eta^{2}=0.397$ \\
\hline FES-I [score] & $19.60 \pm 2.85$ & $16.60 \pm 1.60^{\mathrm{a}, \mathrm{b}}$ & $-|5.3|$ & $19.45 \pm 3.47$ & $18.90 \pm 2.67$ & -2.83 & $<0.001$ & $\eta^{2}=0.159$ \\
\hline \multicolumn{9}{|l|}{$\mathrm{BMD}\left[\mathrm{g} / \mathrm{cm}^{2}\right]$} \\
\hline Lumbar spine absolute & $0.866 \pm 0.112$ & $0.873 \pm 0.122^{b}$ & 0.81 & $0.826 \pm 0.076$ & $0.775 \pm 0.154$ & -6.27 & 0.064 & $\eta^{2}=0.087$ \\
\hline Femoral neck absolute & $0.650 \pm 0.065$ & $0.663 \pm 0.06 \mathrm{I}^{\mathrm{a}}$ & 1.98 & $0.684 \pm 0.068$ & $0.671 \pm 0.050$ & -1.86 & 0.073 & $\eta^{2}=0.082$ \\
\hline
\end{tabular}

Notes: ${ }^{a}$ Significant differences between pre- and post-test $(p<0.05)$; ${ }^{b}$ Significant differences between groups $(p<0.05) ; \eta^{2}=$ partial eta squared; Data are presented as mean values \pm standard deviations of the test measurements before (pre) and after (post) the exercise intervention program; and the percentage of the change between pre- and post-test.

Abbreviations: OLS, one-leg stance; TUG, timed up and go test; ACT, arm curl test; CST, 30-s chair stand test; WT, 6 m walking test; FES-I, Falls Efficacy ScaleInternational; BMD, bone mineral density.

\section{Static Balance and Functional Mobility}

OLS left significantly increased in the IG $(+33 \%, \mathrm{p}<0.001)$ from $17.99 \pm 7.57$ to $23.91 \pm 7.04 \mathrm{~s}$, but remained unchanged in the CG $(p=0.215)$. Within OLS right, IG showed a significant increase compared to baseline testing from $17.80 \pm 7.35$ to $23.58 \pm 7.17 \mathrm{~s}(+33 \%$, $\mathrm{p}<0.001)$, but static postural control remained unchanged in $\mathrm{CG}$ $(\mathrm{p}=0.136)$. IG showed a significant reduction in TUG, compared to the pre-tests from $5.83 \pm 0.95$ to $4.72 \pm 0.83$ s $(-19 \%, p<0.001)$, whereas a significant increase from $5.45 \pm 1.02$ to $5.89 \pm 0.96 \mathrm{~s}(+8 \%, \mathrm{p}=0.014)$ was shown among TUG within CG after intervention completion.

\section{Upper and Lower Limb Muscle Strength}

In the upper limb muscle strength test (ACT), IG showed a significant increase from $15.95 \pm 2.93$ to $21.50 \pm 3.62$ repetitions $(+35 \%, \mathrm{p}<0.001)$. In contrast, $\mathrm{CG}$ exhibited no significant difference in ACT results of pre- and post-tests $(+4 \%, \mathrm{p}=0.117)$. CST significantly increased in the IG $(+36 \%, \mathrm{p}<0.001)$ from $15.55 \pm 3.40$ to $21.20 \pm 3.04$ repetitions, but remained unchanged in the $\mathrm{CG}(+2 \%, \mathrm{p}=0.551)$.

\section{Gait Speed}

The gait speed measured by WT (Figure 3 ) significantly increased in the IG $(+25 \%, \mathrm{p}<0.001)$ from $1.46 \pm 0.33$ to $1.82 \pm 0.30 \mathrm{~m} / \mathrm{s}$, whereas no significant difference was shown among the measured gait speed within $\mathrm{CG}$ $(-6 \%, \mathrm{p}=0.203)$.

\section{FES-I}

IG significantly improved their fall-related self-efficacy $(-15 \%, \mathrm{p}<0.001)$, measured by using the FES-I scores from $19.60 \pm 2.85$ to $16.60 \pm 1.60$ points after intervention completion, but FES-I remained unchanged in the CG $(-3 \%, \mathrm{p}=0.126)$.

\section{BMD}

No significant differences from pre- to post-test for BMD measured at the lumbar spine were found when comparing both groups (Figure 4), IG $(+1 \%, \mathrm{p}=0.289)$ and CG $(-6 \%$, $\mathrm{p}=0.102$ ).

With regard to BMD measured at the femoral neck, IG showed a significant increase compared to baseline testing from $0.650 \pm 0.065$ to $0.663 \pm 0.061 \mathrm{~g} / \mathrm{cm}^{2}(+2 \%$, $\mathrm{p}=0.023)$, but BMD measured at the femoral neck remained unchanged in $\mathrm{CG}(-2 \%, \mathrm{p}=0.630)$.

\section{Discussion}

The primary aim of this randomized controlled pilot study was to evaluate the effectiveness of a combined balance-, strength-, and jumping-exercise intervention performed on a mini-trampoline on static balance and functional mobility, gait speed, strength of the upper and lower limbs, fear of falling, as well as to investigate its influence on the metabolism of BMD.

The main finding of the current study was that all participants of the IG showed significantly different changes compared to $\mathrm{CG}$ in all parameters characterizing 


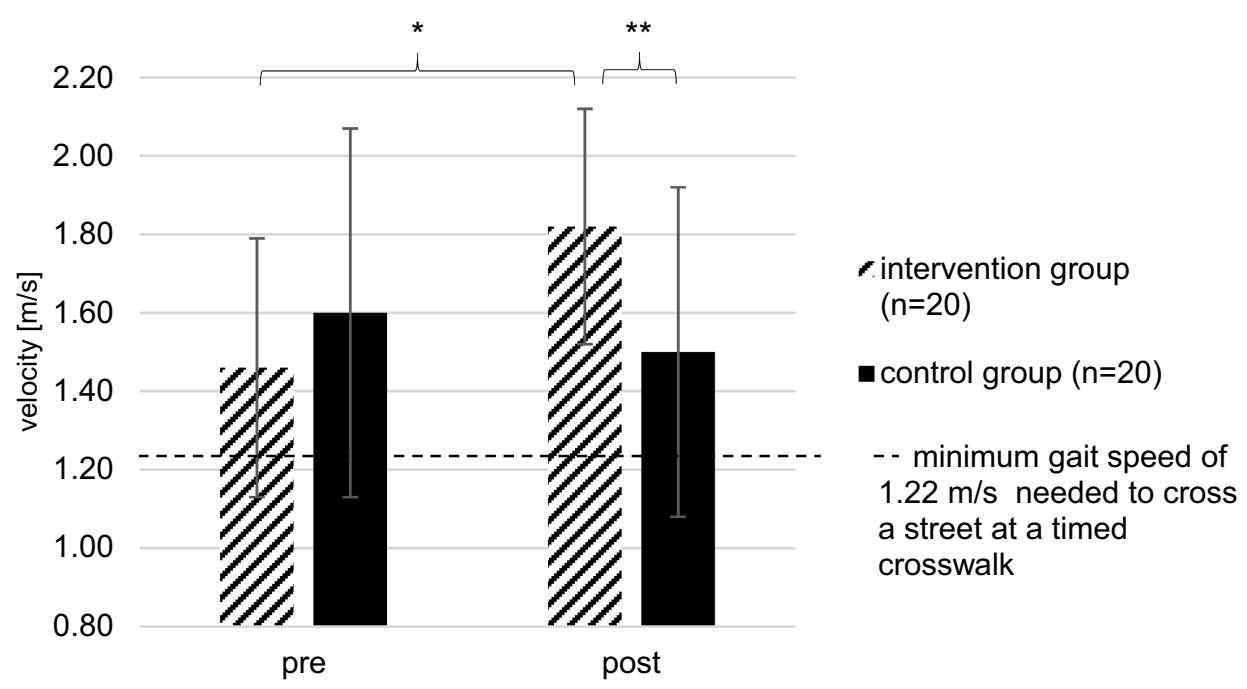

Figure 3 Gait speed measured within WT of IG and CG at pre- and post-tests; ${ }^{*}$ Significant difference between pre- and post-test ( $\left.p<0.05\right)$; ${ }^{* *}$ Significant difference between groups $(p<0.05)$; Data are presented as mean values \pm standard deviations of the WT test measurements before (pre) and after (post) the exercise intervention program.

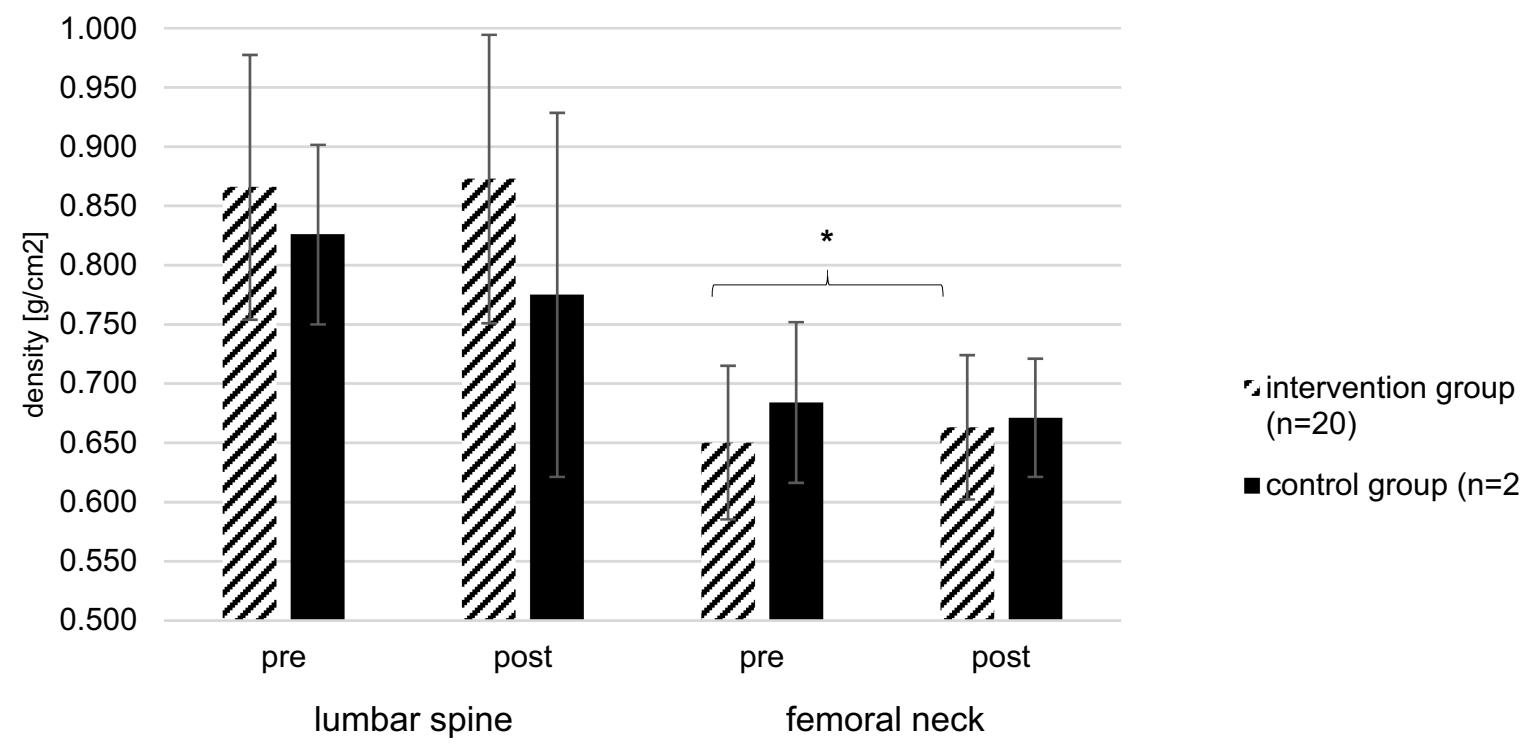

Figure 4 BMD measured at lumbar spine and femoral neck of IG and CG at pre- and post-tests; *Significant difference between pre- and post-test ( $<<0.05$ ); Data are presented as mean values \pm standard deviations of the BMD test measurements before (pre) and after (post) the exercise intervention program.

postural control and functional mobility, strength, gait speed and fear of falling. For BMD no significantly different changes were found.

To the best of our knowledge, there are no studies that investigated the effects of a combined strength-, balance-, and jumping exercise regime performed totally on a minitrampoline on balance, strength, gait speed, fear of falling and its influence on bone mineral density in patients with osteopenia.

After the training intervention program static balance within OLS significantly improved in the IG but remained statistically unchanged in the CG. These results are similar to results reported by studies of Konak et $\mathrm{al}^{33}$ and Otero et $\mathrm{al}^{35}$ who stated that balance ability increased about $37-40 \%$ after training completion within older people with osteoporosis. Although the used training intervention program only lasted 12 weeks compared to the study by Otero et $\mathrm{al}^{35}$ who used a study time period of 24 weeks, an interaction (group $\times$ time) was seen among all OLS test parameters, indicating a significant effect of the exercise regime in the current study. Standing balance on one lower limb is very important among older people as poor postural balance and loss of balance represent the predictor of falls in older people with osteopenia. ${ }^{1,34}$ The TUG, which 
was part of the test battery in this study, measures the functional ability of older people. High functional ability is strongly correlated with the ability of being independent in transfer tasks involved in activities of daily living. ${ }^{49}$ In the underlying study, IG participants needed less time to carry out the TUG, significantly improving 19\% after intervention completion, while $\mathrm{CG}$ needed more time $(8 \%)$ to complete the TUG. Again, a significant interaction (group $\mathrm{x}$ time) was found, reflecting the high effectiveness of the training regime after only 12 weeks. All IG participants decreased their TUG performance to a level below $13.5 \mathrm{~s}$, which indicates, according to a study by ShumwayCook et al, ${ }^{50}$ a special cut-off point for fall risk in older people. In comparison, older people who take more than $13.5 \mathrm{~s}$ are more dependent for most activities of daily living, mobility skills and are more prone to falls. ${ }^{50}$

Besides balance ability and functional mobility, high upper body function including arm strength is important in executing activities of daily living like household chores, carrying groceries and lifting items among older people. ${ }^{51}$ In the present study, IG participants performed significantly more repetitions within the ACT at post-test, whereas the results of $\mathrm{CG}$ remained unchanged, proofing the significant interaction (group $\times$ time). Upper body impairments are associated with dysfunction, the inability to perform personal care activities. ${ }^{64}$ Otero et $\mathrm{al}^{35}$ showed significant improvements in upper limb strength of $80 \%$ after completion of a 24-week low-intensity intervention program, consisting of similar exercise compared to the current study. The improvement was higher than in this study $(35 \%)$, but this could be explained by the fact that the baseline level of upper limb strength was higher among IG participants of the underlying study compared to IG participants in the study of Otero et $\mathrm{al}^{35}$ (15.95 \pm 2.93 vs $10.91 \pm 1.90$ repetitions). It is potentially more difficult to gain muscular adaptions regarding strength due to training among people who are in better physical conditions at baseline. ${ }^{46}$ Anyway, a significant interaction (group $\times$ time) was seen for ACT, indicating the effect of the training regime. Lower limb muscular strength has been well established as a major factor in maintaining functional mobility and preventing or delaying the onset of disability. ${ }^{64,65}$ IG participants of the current study significantly performed more repetitions among the CST after intervention compared to $\mathrm{CG}$. The improvement within the CST reported by Otero et $\mathrm{al}^{33}$ after intervention was higher than in this study (47\% vs 36\%). Again, baseline level of lower limb strength was higher among IG participants of the underlying study compared to IG participants of the study by Otero et $\mathrm{al}^{35}(15.55 \pm 3.40$ vs $13.09 \pm 1.75$ repetitions). Moreover, according to Otero et $\mathrm{al}^{35}$ it seems that for low-intensity training, the duration of the program should be longer to gain improvements in lower limb strength. Nevertheless, a significant interaction (group $\times$ time) was already found among this training intervention program that lasted only 12 weeks.

As mentioned in several studies, ${ }^{54-56}$ gait speed is another good indicator of functional balance, physical performance and falls in older people. The ability to increase gait speed is important during activities of daily living, as when crossing the street or avoiding obstacles. ${ }^{33,46}$ As an example, previous research has proofed that $1.22 \mathrm{~m} / \mathrm{s}$ is a minimum gait speed needed to cross a street at a timed crosswalk. $^{66}$ After the training intervention program, gait speed measured within WT significantly increased from 1.46 to $1.82 \mathrm{~m} / \mathrm{s}$ in the $\mathrm{IG}$, whereas gait speed decreased from 1.60 to $1.50 \mathrm{~m} / \mathrm{s}$ among the CG. Another study has shown that an improvement of $0.10 \mathrm{~m} / \mathrm{s}$ in walking speed is considered as a substantial change ${ }^{56}$ and improves physical function and quality of life. ${ }^{53}$ Therefore, the training intervention program was highly effective in improving gait speed far more than $0.10 \mathrm{~m} / \mathrm{s}$ within all participants of the IG. Furthermore, a significant interaction (group $\times$ time) was found for gait speed measured by the WT. Compared to results of studies by Halvarsson et $\mathrm{al}^{46}$ and Konak et $\mathrm{al}^{33}$ who reported significant improvements in gait speed of $0.08 \mathrm{~m} / \mathrm{s}$ among older people, there was a higher improvement in the underlying study $(0.36 \mathrm{~m} / \mathrm{s})$.

Particularly in patients with osteopenia, falls and lowenergy traumata often lead to fractures. ${ }^{10}$ For this reason, it is important to reduce the level of fear of falling. ${ }^{46}$ Fear of falling significantly decreased among the IG, but remained unchanged within CG. According to a reliability and validity assessment by Halvarsson et al, ${ }^{60}$ the FES-I score has to change more than 2.9 points to ensure a clinically relevant change between groups, as demonstrated by the present findings within IG participants, who changed their scores by 3.0 points.

As approximately $0.25-1 \%$ of BMD is lost per year in premenopausal women, ${ }^{67}$ especially patients with lowered BMD (Osteopenia, Osteoporosis) are predisposed to a high risk of fracture. ${ }^{15}$ According to a study by Kohrt et al, ${ }^{25}$ the primary goal of intervention strategies should be to maintain or reduce age-related loss of BDM. We did not find significant group by time interactions in BMD (lumbar spine or femoral neck) in the present study. However, 
given the relatively short duration of the intervention (12 weeks) and the tendencies found, it seems hard to draw a conclusion on the efficacy of the training intervention on BMD. Future research might therefore address potential effects on BMD using adequately powered studies with a longer intervention time.

Compared to the overview study of Zhao et al, ${ }^{39}$ who reported that jumping exercises proved to be effective in improving BMD at femoral neck, bringing approximately $0.017 \mathrm{~g} / \mathrm{cm}^{2}$ increases, only slightly lower increases of $0.013 \mathrm{~g} / \mathrm{cm}^{2}$ were observed in the current study. This could be explained by the fact, that analyzed studies in the review of Zhao et al ${ }^{39}$ only conducted high-impact jumping exercises on the floor whereas in this study high-impact exercises were performed on a low-impact training device (mini-trampoline), to reduce injury risk. Furthermore, all included studies were conducted with healthy premenopausal women between the ages of 21 and 41 years, compared to the current study, where the mean age of participants of the IG was 70 years. As age increases, the need for ensuring that physical activities can be performed safely arises. Therefore, the applied intensity of jumping exercises was undoubtedly lower in the present study. Not to forget, in their review, Zhao et $\mathrm{al}^{39}$ only included and analyzed studies with a study period ranging from 6 to 12 months.

According to Cummings et al, ${ }^{66,68} \mathrm{BMD}$ of the femoral neck is a better predictor than measurements at the spine, radius and calcaneus. Furthermore, each standard deviation decrease in femoral neck bone density increased the risk of hip fracture 2.6 times. ${ }^{68}$ Therefore, the increment of BMD among femoral neck within IG $(+2 \%)$ was clinically relevant, as the improvement in BMD effectively prevented bone loss and could further decrease the risk of a hip fracture.

Notably, not participating in the intervention program lead to a surprisingly high decrease in BMD at the lumbar spine $(-6 \%)$ and femoral neck (-2\%) among participants of the CG, potentially confirming the importance of exercise interventions. Physical activity is the only intervention that can potentially both, increase BMD and reduce the risk of falling in older people. ${ }^{25}$ To the best of our knowledge, this is the first study that showed significant improvements within postural control and functional mobility, strength, gait speed and fear of falling after a 12week intervention program among older females with osteopenia.

The training intervention program, a multi- and interdisciplinary approach, aimed at using exercises that are easy to replicate in any health- and sports center or even at home. Another special concern was to use measurements that were not only used to their high reliability and validity but rather based on their simplicity. All tests can be performed easily and quickly anywhere by using inexpensive and alternate materials. The underlying training intervention program can be considered as an effective tool to improve balance, strength, gait performance, and fear of falling in a very short time period. Although some results of the underlying study are encouraging, it should be mentioned that both physical activity in general ${ }^{69-71}$ and mini-trampoline training specifically bear some risks for older women. These risks were believed to be minimized in the present study due to specialized instructors, but should be considered when assessing the present intervention.

An important limitation is the lack of an a priori power analysis in the present study. Although trying to contact potential participants using different communication channels, a total sample size of 40 females was attained. However, the sample size was not based on power considerations, but on the aim to get as many participants as possible. Future studies should consider an a priori power analysis whenever possible. As it is known, that recruiting through advertisements in local newspapers may only engage the most interested, physically active and those who are already aware of the importance of specifically tailored interventions, ${ }^{72}$ different ways (TV contributions, personal talks to senior citizen organizations) to recruit participants were applied. Thus, achieving a high training adherence of $100 \%$ was participants of the IG represents a strength of the study. Similar to a study by Halvarsson et $\mathrm{al}^{46}{ }^{46}$ only short-term effects of the combined exercise intervention were statistically analyzed. Furthermore, only participants who fulfilled the study period, were included within a per protocol analysis. It is therefore impossible to evaluate any long-term effects of the intervention. Thus, a long-term follow-up study has already been planned to conduct. It would have been interesting to measure the amount of physical activity of participants pre and post intervention to look whether IG participants have become more physically active resulting in the described improvements. The extent of physical activity will be taken into consideration in our long-term follow-up study. Moreover, the influence of prescribed and applied medication and comorbidities was not taken into account among the statistical analysis. However, study participants were ordered not to change their ingestion of medicine to exclude potential disturbing influences. 
By using a unique combination of test measurements, the effectiveness of the training intervention program on several domains like balance and functional mobility, strength, gait performance, fear of falling and BMD could be investigated for the first time. To prevent a detection bias, the principal investigator (MP), who conducted the test measurements, was blinded to group allocation and was not involved in the intervention. Furthermore, the randomization procedure was conducted by an independent researcher (AS) unaware of the intervention procedures.

\section{Conclusion}

The present study demonstrates favorable effects of a combined balance-, strength-, and jumping-training intervention performed on a mini-trampoline by older women suffering from osteopenia. This intervention was highly effective in improving balance and functional mobility, strength, gait performance and fear of falling in those patients compared to the control group. Therefore, the use of mini-trampoline exercises may be considered as a valuable and safe intervention also for older people.

\section{Acknowledgments}

The authors are deeply grateful to the whole team of the Fliplab Vienna (Austria) for the constructive collaboration and for providing facilities and equipment. Furthermore, the authors would like to thank all participants who took part in the study.

\section{Author Contributions}

Markus Posch: conceptualization, methodology, formal analysis, investigation, resources, data curation, roles/writing - original draft, writing - review and editing, visualization, supervision, project administration. Alois Schranz: conceptualization, methodology, formal analysis, resources, data curation, roles/writing - original draft, writing - review and editing, supervision, project administration. Manfred Lener: conceptualization, methodology, formal analysis, resources, data curation, roles/writing - original draft, writing - review and editing, supervision. Katja Tecklenburg: conceptualization, methodology, formal analysis, resources, data curation, roles/ writing - original draft, writing - review and editing. Martin Burtscher: conceptualization, methodology, formal analysis, investigation, data curation, roles/writing - original draft, writing - review and editing, supervision. Gerhard Ruedl: conceptualization, methodology, formal analysis, investigation, data curation, roles/writing - original draft, writing - review and editing, supervision. Martin Niedermeier: conceptualization, methodology, formal analysis, investigation, data curation, roles/writing - original draft, writing - review and editing, supervision. Werner Wlaschek: conceptualization, methodology, formal analysis, resources, data curation, roles/writing original draft, writing - review and editing, supervision, project administration. All authors contributed to data analysis, drafting or revising the article, gave final approval of the version to be published, and agree to be accountable for all aspects of the work.

\section{Disclosure}

The authors declare no potential conflicts of interests with respect to the research, authorship and/or publication of this article.

\section{References}

1. de Oliveira MR, da Silva RA, Dascal JB, Teixeira DC. Effect of different types of exercise on postural balance in elderly women: a randomized controlled trial. Arch Gerontol Geriat. 2014;59 (3):506-514. doi:10.1016/j.archger.2014.08.009

2. Ganança FF, Gazzola JM, Ganança CF, Caovilla HH, Gananca MM, Cruz OLM. Elderly falls associated with benign paroxysmal positional vertigo. Braz J Otorhinolaryngol. 2010;76(1):113-120. doi:10.1590/S1808-86942010000100019

3. Granacher U, Muehlbauer T, Gollhofer A, Kressig RW, Zahner L. An intergenerational approach in the promotion of balance and strength for fall prevention-a mini-review. Gerontology. 2011;57(4):304-315. doi: $10.1159 / 000320250$

4. Raeissadat SA, Sedighipour L, Pournajaf S, Kashani RV, Sadeghi S. Effect of posture training with weighted kypho-orthosis (WKO) on improving balance in women with osteoporosis. J Aging Res. 2014;2014:1-8. doi:10.1155/2014/427903

5. Maki BE, McIlroy WE. Postural control in the older adult. Clin Geriatr Med. 1996;12(4):635-658. doi:10.1016/S0749-0690(18)30193-9

6. Delbaere K, Crombez G, Vanderstraeten G, Willems T, Cambier D. Fear-related avoidance of activities, falls and physical frailty. A prospective community-based cohort study. Age Ageing. 2004;33 (4):368-373. doi:10.1093/ageing/afh106

7. Reelick MF, van Iersel MB, Kessels RP, Olde Rikkert MGM. The influence of fear of falling on gait and balance in older people. Age Ageing. 2009;38(4):435-440. doi:10.1093/ageing/afp066

8. Scheffer AC, Schuurmans MJ, Van Dijk N, van der Hooft T, de Rooij SE. Fear of falling: measurement strategy, prevalence, risk factors and consequences among older persons. Age Ageing. 2008;37(1):19-24. doi:10.1093/ageing/afm169

9. Gillespie LD, Gillespie WJ, Robertson MC, Lamb SE, Cumming RG, Rowe $\mathrm{BH}$. Interventions for preventing falls in elderly people. Cochrane Db Syst Rev. 2003;(4):CD000340.

10. Weir E, Culmer L. Fall prevention in the elderly population. Can Med Assoc J. 2004;171(7):724. doi:10.1503/cmaj.1041381

11. Kannus P, Sievänen H, Palvanen M, Järvinen T, Parkkari J. Prevention of falls and consequent injuries in elderly people. Lancet. 2005;366 (9500):1885-1893. doi:10.1016/S0140-6736(05)67604-0

12. Kanis JA. Diagnosis of osteoporosis and assessment of fracture risk. Lancet. 2002;359(9321):1929-1936. doi:10.1016/S0140-6736(02) 08761-5

13. Rubenstein LZ, Josephson KR. The epidemiology of falls and syncope. Clin Geriatr Med. 2002;18(2):141-158. doi:10.1016/ S0749-0690(02)00002-2 
14. Riggs BL, Melton Iii LJ. The worldwide problem of osteoporosis: insights afforded by epidemiology. Bone. 1995;17(5):505-511. doi:10.1016/8756-3282(95)00258-4

15. World Health Organization. Assessment of fracture risk and its application to screening for postmenopausal osteoporosis. WHO Technical Report Series. Geneva: World Health Organization; 1994. doi:10.3168/jds.S0022-0302(94)77044-2

16. Kanis JA, McCloskey EV, Johansson H, Cooper C, Rizzoli R, Reginster JY. European guidance for the diagnosis and management of osteoporosis in postmenopausal women. Osteoporosis Int. 2013;24 (1):23-57. doi:10.1007/s00198-012-2074-y

17. Liu J, Zhu LP, Yang XL, Huang HL, Ye DQ. HMG-CoA reductase inhibitors (statins) and bone mineral density: a meta-analysis. Bone. 2013;54(1):151-156. doi:10.1016/j.bone.2013.01.044

18. Johnell O, Kanis J. Epidemiology of osteoporotic fractures. Osteoporosis Int. 2005;16(2):3-7. doi:10.1007/s00198-004-1702-6

19. Yamazaki S, Ichimura S, Iwamoto J, Takeda T, Toyama Y. Effect of walking exercise on bone metabolism in postmenopausal women with osteopenia/osteoporosis. $J$ Bone Miner Metab. 2004;22 (5):500-508. doi:10.1007/s00774-004-0514-2

20. Madureira MM, Takayama L, Gallinaro AL, Caparbo VF, Costa RA, Pereira RMR. Balance training program is highly effective in improving functional status and reducing the risk of falls in elderly women with osteoporosis: a randomized controlled trial. Osteoporosis Int. 2007;18(4):419-425. doi:10.1007/s00198-006-0252-5

21. Kemmler W, von Stengel S, Engelke K, Häberle L, Kalender WA. Exercise effects on bone mineral density, falls, coronary risk factors, and health care costs in older women: the randomized controlled senior fitness and prevention (SEFIP) study. Arch Intern Med. 2010;170(2):179-185. doi:10.1001/archinternmed.2009.499

22. Stolzenberg N, Belavý DL, Rawer R, Felsenberg D. Vibration or balance training on neuromuscular performance in osteopenic women. Int J Sports Med. 2013;34(11):956-962. doi:10.1055/s-00000028

23. Sanders ME, Takeshima N, Rogers ME, Colado JC, Borreani S. Impact of the SWEAT TM water-exercise method on activities of daily living for older women. J Sport Sci Med. 2013;12(4):707.

24. Ponce-Bravo H, Ponce C, Feriche B, Padial P. Influence of two different exercise programs on physical fitness and cognitive performance in active older adults: functional resistance-band exercises vs. recreational oriented exercises. J Sport Sci Med. 2015;14(4):716.

25. Kohrt WM, Bloomfield SA, Little KD, Nelson ME, Yingling VR. American College of Sports Medicine Position Stand: physical activity and bone health. Med Sci Sport Exer. 2004;36(11):1985-1996. doi:10.1249/01.MSS.0000142662.21767.58

26. Castrogiovanni P, Trovato FM, Szychlinska MA, Nsir H, Imbesi R, Musumeci G. The importance of physical activity in osteoporosis. From the molecular pathways to the clinical evidence. Histol Histopathol. 2016;31(11):1183-1194. doi:10.14670/HH-11-793

27. Castrogiovanni P, Musumeci G. Which is the best physical treatment for osteoarthritis? J Funct Morphol Kinesiol. 2016;1(1):54-68. doi:10.3390/jfmk1010054

28. Kidgell DJ, Horvath DM, Jackson BM, Seymour PJ. Effect of six weeks of dura disc and mini-trampoline balance training on postural sway in athletes with functional ankle instability. $J$ Strength Cond Res. 2007;21(2):466.

29. Chilibeck PD, Sale DG, Webber CE. Exercise and bone mineral density. Sports Med. 1995;19(2):103-122. doi:10.2165/00007256-19951902000003

30. Forwood MR, Larsen JA. Exercise recommendations for osteoporosis. Aust Fam Physician. 2000;29(8):761-764.

31. Miklitsch C, Krewer C, Freivogel S, Steube D. Effects of a predefined mini-trampoline training programme on balance, mobility and activities of daily living after stroke: a randomized controlled pilot study. Clin Rehabil. 2013;27(10):939-947. doi:10.1177/0269215513485591
32. Burke TN, FJR F, Meneses SRFD, Pereira RMR, Marques AP. Postural control in elderly women with osteoporosis: comparison of balance, strengthening and stretching exercises. A randomized controlled trial. Clin Rehabil. 2012;26(11):1021-1031. doi:10.1177/ 0269215512442204

33. Konak HE, Kibar S, Ergin ES. The effect of single-task and dual-task balance exercise programs on balance performance in adults with osteoporosis: a randomized controlled preliminary trial. Osteoporosis Int. 2016;27(11):3271-3278. doi:10.1007/s00198-016-3644-1

34. Mikó I, Szerb I, Szerb A, Poor G. Effectiveness of balance training programme in reducing the frequency of falling in established osteoporotic women: a randomized controlled trial. Clin Rehabil. 2017;31 (2):217-224. doi:10.1177/0269215516628616

35. Otero M, Esain I, González-Suarez ÁM, Gil SM. The effectiveness of a basic exercise intervention to improve strength and balance in women with osteoporosis. Clinical Interv Aging. 2017;12 (4):505-513. doi:10.2147/CIA.S127233

36. Behrens M, Müller K, Kilb JI, et al. Modified step aerobics training and neuromuscular function in osteoporotic patients: a randomized controlled pilot study. Arch Orthop Traum Su. 2017;137(2):195-207. doi:10.1007/s00402-016-2607-5

37. Mahoney FI, Barthel DW. Functional evaluation: the Barthel Index: a simple index of independence useful in scoring improvement in the rehabilitation of the chronically ill. Md State Med J. 1965;14:61-65.

38. Howe TE, Rochester L, Neil F, Skelton DA, Ballinger C. Exercise for improving balance in older people. Cochrane Db Syst Rev. 2011;11: CD004963.

39. Zhao R, Zhao M, Zhang L. Efficiency of jumping exercise in improving bone mineral density among premenopausal women: a meta-analysis. Sports Med. 2014;44(10):1393-1402. doi:10.1007/ s40279-014-0220-8

40. Lesinski M, Hortobágyi T, Muehlbauer T, Gollhofer A, Granacher U. Dose-response relationships of balance training in healthy young adults: a systematic review and meta-analysis. Sports Med. 2015;45 (4):557-576. doi:10.1007/s40279-014-0284-5

41. Chodzko-Zajko WJ, Proctor DN, Singh MAF, et al. Exercise and physical activity for older adults. Med Sci Sport Exer. 2009;41 (7):1510-1530. doi:10.1249/MSS.0b013e3181a0c95c

42. Ramalho F, Carnide F, Santos-Rocha R, et al. Community-based exercise intervention for gait and functional fitness improvement in an older population: study protocol. J Aging Phys Activ. 2017;25 (1):84-93. doi: $10.1123 /$ japa.2015-0290

43. Heitmann DK, Gossman MR, Shaddeau SA, Jackson JR. Balance performance and step width in noninstitutionalized, elderly, female fallers and nonfallers. Phys Ther. 1989;69(11):923-931. doi:10.1093/ ptj/69.11.923

44. Frändin K, Sonn U, Svantesson U, Grimby G. Functional balance tests in 76-year-olds in relation to performance, activities of daily living and platform tests. Scand J Rehabil Med. 1995;27(4):231-241.

45. Jarnlo GB, Nordell E. Reliability of the modified figure of eight-a balance performance test for elderly women. Physiother Theor Pr. 2003;19(1):35-43. doi:10.1080/09593980307969

46. Halvarsson A, Franzén E, Ståhle A. Balance training with multi-task exercises improves fall-related self-efficacy, gait, balance performance and physical function in older adults with osteoporosis: a randomized controlled trial. Clin Rehabil. 2015;29(4):365-375. doi: $10.1177 / 0269215514544983$

47. Newton R. Review of tests of standing balance abilities. Brain Injury. 1989;3(4):335-343. doi:10.3109/02699058909004558

48. Bohannon RW. Single limb stance times: a descriptive meta-analysis of data from individuals at least 60 years of age. Top Geriatr Rehabil. 2006;22(1):70-77. doi:10.1097/00013614-200601000-00010

49. Podsiadlo D, Richardson S. The timed "Up \& Go": a test of basic functional mobility for frail elderly persons. $J$ Am Geriatr Soc. 1991;39(2):142-148. doi:10.1111/j.1532-5415.1991.tb01616.x 
50. Shumway-Cook A, Brauer S, Woollacott M. Predicting the probability for falls in community-dwelling older adults using the Timed Up \& Go Test. Phys Ther. 2000;80(9):896-903.

51. Rikli RE, Jones CJ. Development and validation of a functional fitness test for community-residing older adults. J Aging Phys Activ. 1999;7(2):129-161. doi:10.1123/japa.7.2.129

52. McMurdo ME, Rennie L. A controlled trial of exercise by residents of old people's homes. Age Ageing. 1993;22(1):11-15. doi:10.1093/ ageing/22.1.11

53. Studenski S, Perera S, Patel K, et al. Gait speed and survival in older adults. JAMA. 2011;305(1):50-58. doi:10.1001/jama.2010.1923

54. Daley MJ, Spinks WL. Exercise, mobility and aging. Sports Med. 2000;29(1):1-12. doi:10.2165/00007256-200029010-00001

55. Whitehead C, Miller M, Crotty M. Falls in community-dwelling older persons following hip fracture: impact on self-efficacy, balance and handicap. Clin Rehabil. 2003;17(8):899-906. doi:10.1191/ 0269215503 cr695oa

56. Hardy SE, Perera S, Roumani YF, Chandler JM, Studenski SA. Improvement in usual gait speed predicts better survival in older adults. J Am Geriatr Soc. 2007;55(11):1727-1734. doi:10.1111/ (ISSN)1532-5415

57. Karpman C, LeBrasseur NK, DePew ZS, Novotny PJ, Benzo RP. Measuring gait speed in the out-patient clinic: methodology and feasibility. Resp Care. 2014;59(4):531-537. doi:10.4187/respcare.02688

58. Tinetti ME, Richman D, Powell L. Falls efficacy as a measure of fear of falling. J Gerontol. 1990;45(6):239-243. doi:10.1093/geronj/45.6.P239

59. Dias N, Kempen GI, Todd CJ, et al. The German version of the Falls Efficacy Scale-International Version (FES-I). Z Gerontol Geriatr. 2006;39(4):297-300. doi:10.1007/s00391-006-0400-8

60. Halvarsson A, Franzén E, Ståhle A. Assessing the relative and absolute reliability of the Falls Efficacy Scale-International questionnaire in elderly individuals with increased fall risk and the questionnaire's convergent validity in elderly women with osteoporosis. Osteoporosis Intl. 2013;24(6):1853-1858. doi:10.1007/s00198-012-2197-1

61. Faulkner KG, von Stetten E, Miller P. Discordance in patient classification using T-scores. J Clin Densitom. 1999;2(3):343-350. doi: $10.1385 / \mathrm{JCD}: 2: 3: 343$
62. Cummings SR, Bates D, Black DM. Clinical use of bone densitometry: scientific review. JAMA. 2002;288(15):1889-1897. doi:10.1001/ jama.288.15.1889

63. WHO. Prevention and management of osteoporosis. Report. Switzerland: WHO Scientific Group; 2003.

64. Lawrence RH, Jette AM. Disentangling the disablement process. $J$ Gerontol B-Psychol. 1996;51(4):173-182. doi:10.1093/geronb/ 51B.4.S173

65. Gill TM, Williams CS, Richardson ED, Tinetti ME. Impairments in physical performance and cognitive status as predisposing factors for functional dependence among nondisabled older persons. J Gerontol A-Biol. 1996;51(6):283-288. doi:10.1093/gerona/51A.6.M283

66. Langlois JA, Keyl PM, Guralnik JM, Foley DJ, Marottoli RA, Wallace RB. Characteristics of older pedestrians who have difficulty crossing the street. Am J Public Health. 1997;87(3):393-397. doi:10.2105/AJPH.87.3.393

67. Vondracek SF, Hansen LB, McDermott MT. Osteoporosis risk in premenopausal women. Pharmacotherapy. 2009;29(3):305-317. doi:10.1592/phco.29.3.305

68. Cummings SR, Browner W, Black DM, et al. Bone density at various sites for prediction of hip fractures. Lancet. 1993;341(8837):72-75. doi:10.1016/0140-6736(93)92555-8

69. Colbert LH, Hootman JM, Macera CA. Physical activity-related injuries in walkers and runners in the aerobics center longitudinal study. Clin J Sport Med. 2000;10:259-263. doi:10.1097/00042752200010000-00006

70. Hootman JM, Macera CA, Ainsworth BE, Martin M, Addy CL, Blair SN. Association among physical activity level, cardiorespiratory fitness, and risk of musculoskeletal injury. Am J Epidemiol. 2001;154(3):251-258. doi:10.1093/aje/154.3.251

71. Hootman JM, Macera CA, Ainsworth BE, Addy CL, Martin M, Blair SN. Epidemiology of musculoskeletal injuries among sedentary and physically active adults. Med Sci Sports Exerc. 2002;34 (5):838-844. doi:10.1097/00005768-200205000-00017

72. Polit DF, Beck CT. Nursing Research: Generating and Assessing Evidence for Nursing Practice. 8th ed. Philadelphia: Lippincott Williams \& Wilkins; 2008:796.
Clinical Interventions in Aging

\section{Publish your work in this journal}

Clinical Interventions in Aging is an international, peer-reviewed journal focusing on evidence-based reports on the value or lack thereof of treatments intended to prevent or delay the onset of maladaptive correlates of aging in human beings. This journal is indexed on PubMed Central, MedLine, CAS, Scopus and the Elsevier

\section{Dovepress}

Bibliographic databases. The manuscript management system is completely online and includes a very quick and fair peer-review system, which is all easy to use. Visit http://www.dovepress.com/ testimonials.php to read real quotes from published authors. 